\title{
Understanding the Behavioral Consequences of Upward Social Comparison on Social Networking Sites: The Mediating Role of Emotions
}

\author{
Jaeyoung Park ${ }^{1}\left(\mathbb{D}\right.$, Beomsoo Kim $^{1}(\mathbb{D})$ and Sunhee Park ${ }^{2, *(\mathbb{D})}$ \\ 1 Graduate School of Information, Yonsei University, Seoul 03722, Korea; inyourface33@gmail.com (J.P.); \\ beomsookim@gmail.com (B.K.) \\ 2 Barun ICT Research Center, Yonsei University, Seoul 03722, Korea \\ * Correspondence: sunny372@hanmail.net
}

Citation: Park, J.; Kim, B.; Park, S. Understanding the Behavioral

Consequences of Upward Social

Comparison on Social Networking Sites: The Mediating Role of Emotions. Sustainability 2021, 13, 5781 https: / doi.org/10.3390/su13115781

Academic Editor: Bongsug

(Kevin) Chae

Received: 2 May 2021

Accepted: 19 May 2021

Published: 21 May 2021

Publisher's Note: MDPI stays neutral with regard to jurisdictional claims in published maps and institutional affiliations.

Copyright: (c) 2021 by the authors. Licensee MDPI, Basel, Switzerland. This article is an open access article distributed under the terms and conditions of the Creative Commons Attribution (CC BY) license (https:/ / creativecommons.org/licenses/by/ $4.0 /)$.

\begin{abstract}
With the increase in upward social comparison occurring on social networking sites (SNSs) globally, SNS researchers have examined the impact of upward social comparison. However, they focused mainly on psychological outcomes (e.g., well-being). To extend the existing studies, this study investigates the behavioral consequences of upward social comparison through the underlying mechanisms of emotions. Drawing on Smith's typology of social comparison-based emotions, we developed a conceptual model that integrates upward social comparison on Instagram, upward comparison emotions (upward contrastive emotions and upward assimilative emotions), and the behavioral responses (SNS discontinuance, posting of comments). A structural equation modeling analysis revealed that upward social comparison in Instagram usage provoked upward contrastive emotions including anger, depression, and envy, which, in turn, induced Instagram discontinuance and the posting of malicious comments on Instagram. Additionally, upward assimilative emotions including admiration, optimism, and inspiration triggered the posting of favorable comments on Instagram. This study enhances our understanding of SNS social comparison by revealing how upward social comparison on Instagram is related to behavioral consequences.
\end{abstract}

Keywords: upward social comparison; upward contrastive emotions; upward assimilative emotions; malicious comments; favorable comments; social networking site; SNS discontinuance

\section{Introduction}

The use of social networking sites (SNSs) has various behavioral consequences for users, one of which is SNS discontinuance. Recently, many users have been leaving SNSs. For example, Facebook has been experiencing a decline in users since 2017 [1]. The departure of users can threaten the sustainability of SNS platforms [2]. Another potential behavioral consequence of SNS usage is posting comments. People often post malicious comments on SNSs, a form of cyberbullying, which can cause great harm to the receiver [3]. In South Korea, a popular K-pop star committed suicide in 2019 after suffering malicious and abusive comments on SNSs. Jang et al. [4] stated that there is a need to encourage people to write benevolent (favorable) comments and to reduce malicious comments, thus fostering healthy online communities. Then, what makes people quit SNSs? What is causing people to post malicious or favorable comments on SNSs? One such factor may be upward social comparison.

According to social comparison theory, people naturally compare themselves to others to evaluate their relative status [5]. Social comparisons are classified into two types: upward comparison (with others who are better off) and downward comparison (with others who are worse off) [6]. With the prevalence of SNSs, people have compared themselves to others not only offline but also on SNSs. Since content posted on SNSs is often overly positive rather than negative [7], SNS users are likely to engage more in upward social comparison. 
It has been noted that upward social comparison on SNSs leads to both psychological and behavioral responses $[8,9]$. However, previous studies have mainly focused on the psychological consequences of upward social comparison such as depressive symptoms [10-13], life satisfaction [14,15], and subjective well-being [16,17]. As Krasnova et al. [18] pointed out, little is known about what behavior upward social comparison on SNSs leads to, and more importantly, about the underlying mechanism of this relationship.

Thus, this study aims to address the research question of whether and how upward social comparison is related to the following behavioral responses that have been ignored in previous studies: SNS discontinuance, the posting of malicious comments, and the posting of favorable comments. Consistent with previous studies $[19,20]$, we believe that upward social comparison will not directly cause the behavioral responses, but it will affect behavioral responses through certain factors. We expect that SNS-induced emotions are an important underlying psychological mechanism in this relationship. In other words, upward social comparison will trigger negative and/or positive emotions, and these emotions will lead to behavioral responses.

According to Smith's typology of social comparison-based emotions, upward social comparison induces upward comparison emotions: upward contrastive and upward assimilative emotions [21]. The former is a set of negative emotions induced by upward social comparison including anger/resentment (toward others), depression (toward the self), and envy (toward others and the self), while the latter is a set of positive emotions induced by upward social comparison including admiration (toward others), optimism (toward the self), and inspiration (toward others and the self).

Negative or positive emotions induced by upward social comparison on SNSs may lead to a particular behavior [22,23]. For example, Wenninger et al. [2] found that envy on Facebook is related to three behavioral consequences: self-enhancement, gossiping, and discontinuance intention. However, very few studies have comprehensively examined the relationship between upward social comparison, emotions, and behavioral responses in the context of Instagram, where upward social comparison occurs more often compared to other SNSs.

To offer a better understanding of the behavioral responses of upward social comparison on SNSs, we first examined whether upward social comparison triggers upward comparison emotions (i.e., upward contrastive emotions and upward assimilative emotions) in the Instagram context. Second, we investigated whether upward contrastive and upward assimilative emotions lead to the behavioral responses (Instagram discontinuance intention, the posting of malicious and positive comments). Finally, we explored the mediating role of upward comparison emotions in the association between upward social comparison on Instagram and three behavioral responses. To achieve the purpose of this study, an online survey was conducted with active Instagram users in South Korea and structural equation modeling (SEM) analysis was performed using Mplus 8.0 with data from 330 Instagram users.

\section{Theoretical Background and Hypotheses Development}

\subsection{Upward Social Comparison on SNSs and Its Impact}

SNSs allow users to learn about others' lives, which leads to upward social comparison [24]. Existing studies have found that upward social comparison is linked to unfavorable psychological outcomes $[10-14,20]$. The main reason for these results is that comparison with people who look better than oneself causes negative emotions such as (malicious) envy or relative deprivation $[10,13,14]$. However, upward social comparison can also elicit positive emotions (e.g., benign envy), because comparison with people who are better than them can motivate individuals to improve their lives $[25,26]$. Furthermore, Meier et al. [27] found that people could be inspired by engaging in upward comparison on SNSs, which can increase their well-being. Prior findings demonstrate that emotions elicited by upward social comparison can affect individual psychological consequences. 
However, emotions can also lead to certain behavioral consequences [22,23]. Recently, in the context of SNSs, Latif et al. [19] found that malicious envy mediates the positive relationship between social comparison on Facebook and negative gossiping about Facebook friends, one of the potential behavioral outcomes. Nevertheless, there is still a lack of understanding of the behavioral responses of upward social comparison. In other words, there will be more behavioral responses than those identified in prior studies [2]. Thus, we seek to uncover the process through which social comparison on SNSs is positively related to upward comparison emotions, eventually leading to SNS discontinuance, the posting of malicious comments, and the posting of favorable comments.

\subsection{Upward Social Comparison and Upward Comparison Emotions}

When users see posts by other people who seem to be doing great in life, they can feel negative or positive emotions; this is determined by the contrast-assimilation process [28] If SNS users focus on relational differences with the comparison targets and what upholds them, then contrastive comparisons take place, leading to negative emotions such as anger, depression, and envy (i.e., upward contrastive emotions). Previous studies have shown that upward social comparison on SNSs is followed by negative emotions such as malicious envy $[10,26,27]$.

In contrast, if the focus of SNS users is on relational similarities with the comparison targets, and the motivation is to become similar to the targets, then an assimilative comparison arises, leading to positive emotions such as admiration, optimism, and inspiration (i.e., upward assimilative emotions). Recent studies have shown that positive emotions such as benign envy can result from upward comparison on SNSs $[19,26,27]$. In addition, a positive relationship was found between benign envy and inspiration [25]. Following this, we hypothesize:

Hypothesis 1 (H1). Upward social comparison on SNSs would positively relate to (a) upward contrastive emotions and (b) upward assimilative emotions.

\subsection{Upward Contrastive Emotions and Behavioral Responses}

In the organizational and offline context, the envier experiencing envy toward a person perceived as superior tries to avoid the envied person or the envy-inducing situation [29,30]; this is called an avoidance strategy. Likewise, SNS users experiencing negative emotions due to other people's posts may employ a similar avoidance strategy. For example, since users no longer wish to experience negative upward comparison emotions from SNS activities, users may switch to alternative SNS platforms [20] or leave Facebook entirely to avoid inducing malicious envy [2]. Thus, we hypothesize the following:

Hypothesis 2 (H2a). Upward contrastive emotions are positively related to SNS discontinuance intention.

Negative emotions can also lead to malicious (antisocial) behaviors toward others. Perceiving another person in a group as superior induces hostility, which results in harmful behaviors toward that person [31]. In the SNS context, recent research has also shown that envy toward other users leads to gossiping with the intent to level down the superior others encountered on SNSs [2,19]. Another such harmful behavior on SNSs is the posting of malicious comments with the intent to hurt others, which constitutes a relatively more direct and frequent action that has been understudied in previous research. Many people post malicious comments online to express feelings of inferiority and frustration [32].

People also often post favorable comments online. Favorable comments can be considered one form of prosocial behavior displayed online [33]. Prosocial behavior is defined as voluntary behavior that is done with the aim of benefiting others [34]. Indepth interviews with online community users have shown encouragement (e.g., "encourage/praise/support someone") as the most frequent reason and motivation for posting favorable (benevolent) comments [32]. 
Unfortunately, however, negative emotions can undermine such motivations. For example, it is unlikely that sympathetic comments will be posted during an emotional state of anger or self-perceived inferiority caused by another person's content. Previous research has shown that anger reduces prosocial behavior [34]. Applying this to the context of SNSs, it can be expected that users with negative emotions will try less often to post favorable comments. Consequently, we hypothesize:

Hypothesis $2 \mathbf{( H 2 b ) . ~ U p w a r d ~ c o n t r a s t i v e ~ e m o t i o n s ~ a r e ~ p o s i t i v e l y ~ r e l a t e d ~ t o ~ p o s t i n g ~ o f ~ m a l i - ~}$ cious comments.

Hypothesis $2 \mathbf{( H 2 c ) . ~ U p w a r d ~ c o n t r a s t i v e ~ e m o t i o n s ~ a r e ~ n e g a t i v e l y ~ r e l a t e d ~ t o ~ p o s t i n g ~ o f ~ f a v o r - ~}$ able comments.

\subsection{Upward Assimilative Emotions and Behavioral Responses}

Contrary to upward contrastive emotions, upward assimilative emotions can lower SNS discontinuance intention. Users can gain positive motivation from another people's success and believe that they can likewise reach success. Such positivity toward life or positive stimulation from others through the use of SNSs will result in the user's positive perception of SNS use by the user [26]. In other words, the more positive users feel while using SNSs, the more satisfied users will feel about the SNS. SNS satisfaction is negatively related to SNS discontinuance intention [2]. Thus, we hypothesize the following:

Hypothesis 3 (H3a). Upward assimilative emotions are negatively related to SNS discontinuance intention.

Upward assimilative emotions can reduce online antisocial behaviors. The posting of malicious comments can be seen as antisocial behavior, causing harm to others online. Posting comments online is a behavior in response to another person's online content, and behavioral responses are closely related to emotions [22,23]. People experiencing positive emotions tend not to display behavior that is harmful to others. Several studies support this argument. Richaud and Mesurado [35] found that positive emotions inhibit aggressive behavior. Furthermore, it has been shown that positive emotion training successfully reduces aggressive behavior [36]. Empirical evidence suggests that positive emotions can play an important role in preventing actions that harm others.

Not only can positive emotions reduce malicious behavior toward others, they can also lead to favorable behavior for others. Aknin et al. [37] stated that positive emotions encourage prosocial behavior. In addition, it has been shown that positive emotions result in online prosocial behavior (e.g., "say nice things to someone") [38]. Thus, we hypothesize the following:

Hypothesis $3 \mathbf{~}(\mathbf{H} 3 \mathbf{b})$. Upward assimilative emotions are negatively related to posting of malicious comments.

Hypothesis $3 \mathbf{~}(\mathbf{H} 3 \mathbf{c})$. Upward assimilative emotions are positively related to posting of favorable comments.

Prior studies have shown that upward social comparison affected psychological and behavioral outcomes through emotions (e.g., malicious envy, benign envy) [19,20,25,39]. For example, Latif et al. [19] found that social comparison elicits malicious envy, which, in turn, leads to negative gossiping. This suggests that SNS-induced emotions play an important role in the relationship between social comparison and the related outcomes. Thus, we expect that upward comparison emotions (upward contrastive emotions and upward assimilative emotions) will mediate the association between upward social comparison and three behavioral responses (SNS discontinuance, the posting of malicious comments, and the posting of favorable comments), respectively. 


\section{Conceptual Model and Methodology}

\subsection{Conceptual Model}

Based on the existing literature, we comprehensively examined the relationship between upward social comparison, upward comparison emotions (i.e., upward contrastive emotions and upward assimilative emotions), and three behavioral responses (i.e., SNS discontinuance, the posting of malicious comments, and the posting of favorable comments; Figure 1).

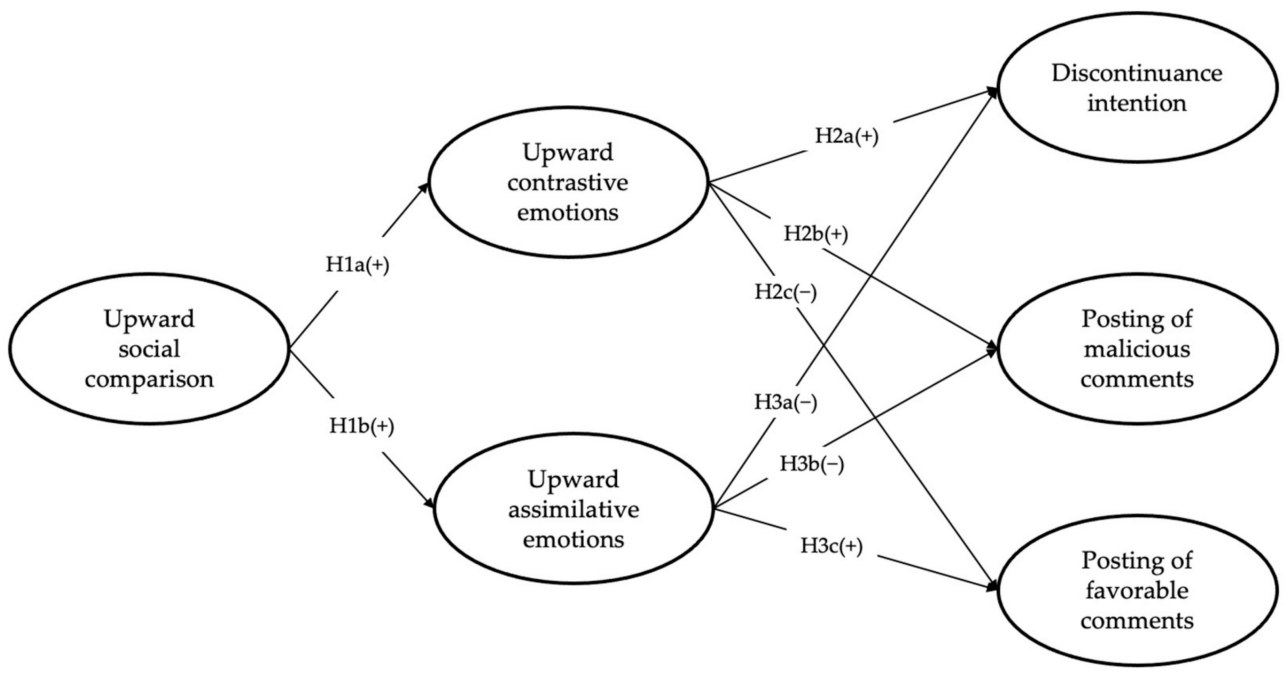

Figure 1. Conceptual model.

\subsection{Participants and Data Collection}

The target population of our study was Instagram users in South Korea. The inclusion criteria for the participants were as follows: aged between 20 and 49 years, active Instagram user, and consented to participating in the study. A recent survey conducted in South Korea showed that Instagram is used by a wide range of age groups, from users in their $20 \mathrm{~s}$ to users in their 40s [40]. Furthermore, since Instagram is a popular image-based SNS in which positive self-presentation is very common, it is the most relevant SNS platform for examining upward social comparison. Therefore, we believe that our sample is appropriate for achieving the purpose of the study.

In August 2019, an online survey was conducted through a leading online survey company to ensure the representativeness of the sample. The link to participate in the survey was distributed to its panels via email. The first part of the survey provided instructions and the purpose of the study. It was clearly stated that no personal information that could be used to identify the participants would be collected. Participation was completely voluntary, and the participants could discontinue their engagement with the study at any stage. Since this study targeted active Instagram users, participants who did not use Instagram were excluded from the survey. Informed consent was received from all participants through an opt-in question at the beginning of the survey. A total of 1172 people from the panel were extracted via quota sampling based on age and gender; ultimately, 330 valid questionnaires were collected.

Table 1 presents the characteristics of the participants such as age, gender, daily minutes spent on Instagram, and number of Instagram followers. Women comprised $51.82 \%$ of the participants. The mean age of the participants was 34.05 years $(\mathrm{SD}=8.25)$. In terms of Instagram use, $33.9 \%$ used it for 10-30 min daily, and the mean follower count of the participants was 153.2 people $(\mathrm{SD}=314.2)$. 
Table 1. Characteristics of the participants $(n=330)$.

\begin{tabular}{cccc}
\hline Characteristics & Item & Frequency & Percentage \\
\hline \multirow{2}{*}{ Gender } & Male & 159 & 48.2 \\
& Female & 171 & 51.8 \\
\hline \multirow{2}{*}{ Age } & $20 \sim 29$ & 115 & 34.9 \\
$(\mathrm{M}=34.05, \mathrm{SD}=8.25)$ & $30 \sim 39$ & 109 & 33.0 \\
& $40 \sim 49$ & 106 & 32.1 \\
\hline & $<10 \mathrm{~min}$ & 49 & 14.8 \\
Daily minutes spent on Instagram & $10-30 \mathrm{~min}$ & 112 & 33.9 \\
$(\mathrm{M}=2.7, \mathrm{SD}=1.2)$ & $30-60 \mathrm{~min}$ & 87 & 26.4 \\
& $60-120 \mathrm{~min}$ & 47 & 14.2 \\
& $>120 \mathrm{~min}$ & 35 & 10.6 \\
\hline & $<30$ & 77 & 23.3 \\
Number of Instagram followers & $30-100$ & 104 & 31.5 \\
$(\mathrm{M}=153.2, \mathrm{SD}=314.2)$ & $100-300$ & 106 & 32.1 \\
& $>300$ & 43 & 13.0 \\
\hline
\end{tabular}

\subsection{Measurements}

\subsubsection{Upward Social Comparison}

In this study, upward social comparison on Instagram refers to comparing one's accomplishments, situation, and experiences with those who are perceived to be better off on Instagram [41,42]. We used the measures originally developed by Solberg et al. [43]. Participants were asked to report their agreement with each of five statements; for example, "Generally when I use Instagram I often compare myself with people who have a better daily life than I do." The items were rated on a 5-point Likert-type scale $(1=$ strongly disagree, $5=$ strongly agree). The Cronbach's $\alpha$ in this study was 0.941 .

\subsubsection{Upward Comparison Emotions}

Upward contrastive emotions were measured with six items addressing envy, depression, frustration, inferiority, anger, and resentment, respectively, while upward assimilative emotions were measured with three items addressing admiration, inspiration, and optimism, with reference to the study of Park and Baek [44]. Participants were asked to report how much they felt each emotion when they used Instagram (e.g., "When I use Instagram I often envy others"). The items were rated on a 5-point Likert-type scale ( $1=$ never, $5=$ always). In this study, the Cronbach's $\alpha$ values for upward contrastive emotions and upward assimilative emotions were 0.926 and 0.729 , respectively.

\subsubsection{Behavioral Responses}

In this study, behavioral responses represented the following: (1) Instagram discontinuance intention and (2) the posting of comments on Instagram.

Instagram discontinuance intention was developed based on the study by Luqman et al. [45], and it was measured by four items. Participants were asked to report their agreement with each statement; for example, "I plan to stop using this social networking website soon". The items were rated on a 5-point Likert-type scale $(1=$ strongly disagree, $5=$ strongly agree). In this study, the Cronbach's $\alpha$ for Instagram discontinuance intention was 0.900 .

The posting of comments on Instagram was assessed based on Kim et al. [3] and Jang et al. [4] using six items, including three items related to malicious comments (e.g., "I usually post comments that disparage others while using Instagram") and three items related to favorable comments (e.g., "I usually post comments that compliment others while using Instagram"). The items were rated on a 5-point Likert-type scale ( $1=$ never, $5=$ always) In this study, the Cronbach's $\alpha$ values for the posting of malicious comments and favorable comments were 0.963 and 0.917 , respectively. 


\subsubsection{Control Variables}

For statistical controls, daily minutes spent on Instagram and the number of Instagram followers, as well as participant demographics such as age and gender, were included in the SEM analysis [19]. Daily minutes spent on Instagram was measured by the question "How much do you use Instagram on average per day?" ( $1=$ less than $10 \mathrm{~min}, 2=10-30 \mathrm{~min}$, $3=30-60 \mathrm{~min}, 4=60-120 \mathrm{~min}, 5=$ more than $120 \mathrm{~min}$ ). Participants were also asked to enter their number of Instagram followers.

\section{Data Analysis and Results}

Data were analyzed using Mplus 8.0. First, confirmatory factor analysis (CFA) was conducted to test the relationship among the factors and related items and to evaluate convergent validity, reliability, and discriminant validity [46]. The convergent validity used the three standards recommended by Bagozzi and Yi [47] to assess the measurement model: factor loadings of all items (should exceed 0.5), the composite reliability (CR) of the construct (should be above 0.7), and average variance extracted (AVE) values (should exceed 0.5). To assess whether the model fit adequately to the data, several fit indices were considered: (1) the ratio of $\chi^{2}$ over the degrees of freedom $\left(\chi^{2} / \mathrm{df}\right.$; should be less than 6), (2) root-mean-square error of approximation (RMSEA; should be less than 0.08), (3) comparative fit index (CFI; should be more than 0.90), Tucker-Lewis index (TLI; should be more than 0.90 ), and the standardized root-mean-square residual (SRMR; should be less than 0.90).

Next, the structural model and hypothesis testing were conducted via SEM in Mplus 8.0 [48]. We estimated the coefficients and tested the significance of the proposed relationships using maximum likelihood estimation. In SEM, the latent variables of upward comparison, upward contrastive emotions, upward assimilative emotions, Instagram discontinuance intention, the posting of malicious comments, and the posting of favorable comments had six packs, divided by item content. The measurement model above would be transformed into a structural model to validate the hypotheses. For the evaluation of the proposed model, the coefficient of determination $\left(R^{2}\right)$ and the significance levels of the path coefficient were observed [49]. A bootstrapping procedure was used to test the statistical significance of the paths and indirect effects in each model. The bias-corrected $95 \%$ confidence interval (CI) of 1000 resamples was calculated, following established statistical advice [50].

\subsection{Analyses of Convergent and Discriminant Validity across Constructs}

In the first stage, CFA provided evidence of good model fit $\left(\chi^{2}=411.626(\mathrm{df}=225\right.$, $p=0.000), \mathrm{CFI}=0.972$, TLI $=0.965$, RMSEA $(90 \% \mathrm{CI}=0.050(0.042-0.058), \mathrm{SRMR}=0.045)$. The indicator factor loadings of all items were $0.569-0.912$. The $\mathrm{CR}$ of the construct was $0.754-0.946$. AVE values were $0.512-0.854$. These factors produced acceptable results in other complementary indices, prompting us to retain them (Table 2).

Regarding discriminant validity, the AVE of the construct should be greater than the other correlation coefficients of the construct [51]. Table 3 shows that the correlation coefficients between any two constructs are smaller than the square root of the AVE for the constructs; these results indicated that all of the constructs in our study had sufficient discriminant validity.

Thus, the constructs of the measurement model in the present study showed satisfactory reliability, convergent validity, and discriminant validity. 
Table 2. Confirmatory factor analysis.

\begin{tabular}{|c|c|c|c|c|c|}
\hline Constructs & Item & Factor Loading & C.R. & AVE & Cronbach's $\alpha$ \\
\hline \multirow{5}{*}{$\begin{array}{c}\text { Upward } \\
\text { social } \\
\text { comparison }\end{array}$} & USC1 & 0.844 & \multirow{5}{*}{0.915} & \multirow{5}{*}{0.730} & \multirow{5}{*}{0.941} \\
\hline & USC2 & 0.875 & & & \\
\hline & USC3 & 0.856 & & & \\
\hline & USC4 & 0.898 & & & \\
\hline & USC5 & 0.908 & & & \\
\hline \multirow{6}{*}{$\begin{array}{l}\text { Upward } \\
\text { contrastive } \\
\text { emotions }\end{array}$} & UCE1 & 0.807 & \multirow{6}{*}{0.925} & \multirow{6}{*}{0.674} & \multirow{6}{*}{0.926} \\
\hline & UCE2 & 0.874 & & & \\
\hline & UCE3 & 0.887 & & & \\
\hline & UCE4 & 0.864 & & & \\
\hline & UCE5 & 0.784 & & & \\
\hline & UCE6 & 0.693 & & & \\
\hline \multirow{3}{*}{$\begin{array}{c}\text { Upward } \\
\text { assimilative } \\
\text { emotions }\end{array}$} & UAE1 & 0.569 & \multirow{3}{*}{0.754} & \multirow{3}{*}{0.512} & \multirow{3}{*}{0.729} \\
\hline & UAE2 & 0.855 & & & \\
\hline & UAE3 & 0.693 & & & \\
\hline \multirow{4}{*}{$\begin{array}{l}\text { Instagram } \\
\text { discontinuance } \\
\text { intention }\end{array}$} & DISC1 & 0.886 & \multirow{4}{*}{0.859} & \multirow{4}{*}{0.683} & \multirow{4}{*}{0.900} \\
\hline & DISC2 & 0.880 & & & \\
\hline & DISC3 & 0.848 & & & \\
\hline & DISC4 & 0.674 & & & \\
\hline \multirow{3}{*}{$\begin{array}{l}\text { Posting of } \\
\text { malicious } \\
\text { comments }\end{array}$} & MC1 & 0.890 & \multirow{3}{*}{0.946} & \multirow{3}{*}{0.854} & \multirow{3}{*}{0.963} \\
\hline & MC2 & 0.880 & & & \\
\hline & MC3 & 0.997 & & & \\
\hline \multirow{3}{*}{$\begin{array}{l}\text { Posting of } \\
\text { favorable } \\
\text { comments }\end{array}$} & FC1 & 0.867 & \multirow{3}{*}{0.918} & \multirow{3}{*}{0.788} & \multirow{3}{*}{0.917} \\
\hline & FC2 & 0.883 & & & \\
\hline & FC3 & 0.912 & & & \\
\hline
\end{tabular}

Note: $\mathrm{CR}=$ composite reliability; $\mathrm{AVE}=$ average variance estimation. $\chi^{2}=411.626(\mathrm{df}=225), \mathrm{CFI}=0.972$, $\mathrm{TLI}=0.965, \mathrm{SRMR}=0.045, \mathrm{RMSEA}=0.050(0.042 \sim 0.058)$.

Table 3. Correlation matrix and discriminant validity.

\begin{tabular}{|c|c|c|c|c|c|c|}
\hline & 1 & 2 & 3 & 4 & 5 & 6 \\
\hline $\begin{array}{l}\text { 1. Upward social } \\
\text { comparison }\end{array}$ & 0.854 & & & & & \\
\hline $\begin{array}{l}\text { 2. Upward contrastive } \\
\text { emotions }\end{array}$ & $0.705^{* * *}$ & 0.821 & & & & \\
\hline $\begin{array}{l}\text { 3. Upward assimilative } \\
\text { emotions }\end{array}$ & 0.065 & -0.012 & 0.716 & & & \\
\hline $\begin{array}{c}\text { 4. Instagram } \\
\text { discontinuance intention }\end{array}$ & $0.231^{* * *}$ & $0.402^{* * *}$ & -0.054 & 0.826 & & \\
\hline $\begin{array}{l}\text { 5. Posting of malicious } \\
\text { comments }\end{array}$ & $0.277^{* * *}$ & $0.441^{* * *}$ & -0.068 & $0.432 * * *$ & 0.924 & \\
\hline $\begin{array}{l}\text { 6. Posting of favorable } \\
\text { comments }\end{array}$ & $0.207^{* * *}$ & 0.144 * & $0.282^{* * *}$ & 0.068 & $0.209^{* * *}$ & 0.888 \\
\hline
\end{tabular}

Note: diagonal values are the square root of AVE; $: p<0.05 ; * * *: p<0.001$

\subsection{Structural Model and Hypothesis Testing}

In the second stage, SEM was conducted to test the hypothesized paths among the latent variables. It provided evidence of good model fit $\left(\chi^{2}=518.179(\mathrm{df}=313, p=0.000)\right.$, $\mathrm{CFI}=0.961, \mathrm{TLI}=0.953, \mathrm{RMSEA}(90 \% \mathrm{CI}=0.051(0.044-0.057), \mathrm{SRMR}=0.050)$. As shown in Figure 2, first, upward comparison on Instagram was positively related to upward contrastive emotions $(\beta=0.703, p=0.000)$, while upward comparison on Instagram was not related to upward assimilative emotions $(\beta=0.067, p=303)$. Therefore, H1a was supported, while H1b was not supported.

Second, as we expected, upward contrastive emotions were positively related to Instagram discontinuance intention $(\beta=0.398, p=0.000)$ and the posting of malicious 
comments ( $\beta=0.432, p=0.000$ ); however, contrary to our hypothesis, upward contrastive emotions were positively, not negatively, related to the posting of favorable comments ( $\beta=0.144, p=0.008)$. Hence, H2a and H2b were supported, but H2c was not supported.

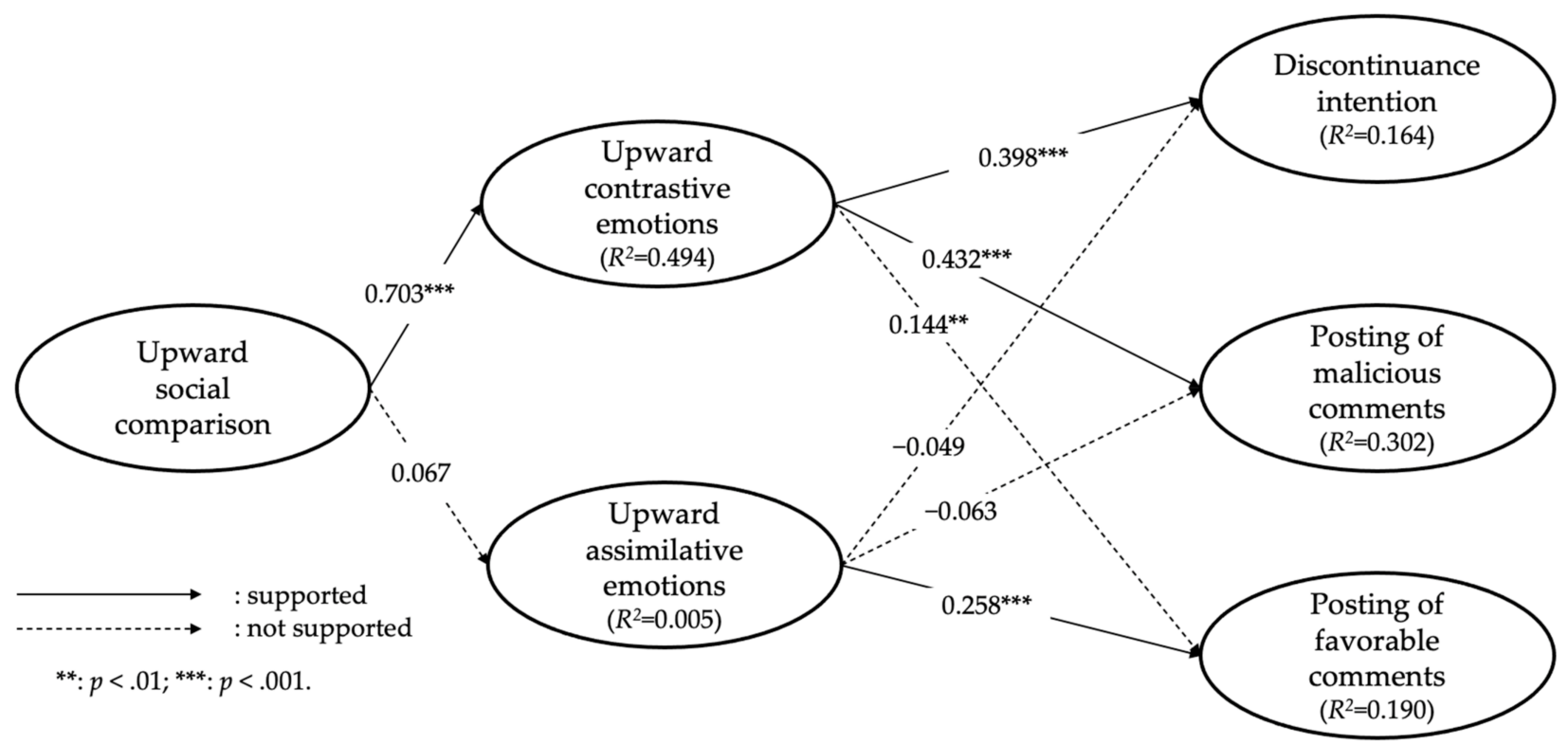

Figure 2. Hypothesis testing results of the proposed model. Note: in SEM analysis, we included gender, age, daily minutes spent on Instagram, and number of Instagram followers as control variables. Fit indices are $\chi^{2}=578.179(\mathrm{df}=313, p=0.000)$, $\mathrm{CFI}=0.961, \mathrm{TLI}=0.953, \mathrm{RMSEA}(90 \% \mathrm{CI}=0.051(0.044-0.057), \mathrm{SRMR}=0.050)$.

Finally, the relationships of upward assimilative emotions with Instagram discontinuance intention ( $\beta=-0.049, p=0.424)$ and the posting of malicious comments ( $\beta=-0.063$, $p=0.237)$ were not significant, while upward assimilative emotions were positively related to the posting of favorable comments ( $\beta=0.258, p=0.000$ ). Thus, $\mathrm{H} 3 \mathrm{c}$ was supported, but $\mathrm{H} 3 \mathrm{a}$ and $\mathrm{H} 3 \mathrm{~b}$ were not supported.

\subsection{The Mediating Effects of Upward Comparison Emotions}

To verify whether upward comparison affects three behavioral responses through upward comparison emotions, we analyzed the mediating effects of upward contrastive emotions and upward assimilative emotions in the relationship between upward comparison and three behavioral responses. The results revealed that the paths between upward comparison and Instagram discontinuance intention, the posting of malicious comments, and the posting of favorable comments were mediated by upward contrastive emotions but not by upward assimilative emotions (Table 4). Therefore, our results indicate that upward comparison triggers upward contrastive emotions, resulting in higher discontinuance intention, the posting of malicious comments, and the posting of favorable comments. 
Table 4. Results of the mediating effect of upward comparison emotions.

\begin{tabular}{|c|c|c|c|c|c|c|c|}
\hline \multicolumn{3}{|c|}{ Variable } & \multicolumn{3}{|c|}{ Indirect Effect (IV-M-DV) } & \multirow{2}{*}{$\begin{array}{c}\text { Mediating } \\
\text { Effect }\end{array}$} & \multirow{2}{*}{$\begin{array}{c}\text { Bootstrap } \\
\text { Confidence } \\
\text { Interval }\end{array}$} \\
\hline IV & $\mathbf{M}$ & DV & $\begin{array}{c}\text { Standardized } \\
\text { Coefficient }\end{array}$ & C.R. & $p$-Value & & \\
\hline UC & UCE & DISC & 0.279 & 7.088 & 0.000 & Significant & $0.194 \sim 0.368$ \\
\hline UC & UCE & $\mathrm{MC}$ & 0.304 & 8.453 & 0.000 & Significant & $0.238 \sim 0.367$ \\
\hline UC & UCE & $\mathrm{FC}$ & 0.101 & 2.617 & 0.009 & Significant & $0.027 \sim 0.178$ \\
\hline UC & UAE & DISC & -0.003 & -0.618 & 0.536 & $\begin{array}{c}\text { Not } \\
\text { Significant }\end{array}$ & $-0.0023 \sim 0.010$ \\
\hline UC & UAE & $\mathrm{MC}$ & -0.004 & -0.775 & 0.438 & $\begin{array}{c}\text { Not } \\
\text { Significant }\end{array}$ & $-0.028 \sim 0.009$ \\
\hline UC & UAE & FC & 0.017 & 0.982 & 0.326 & $\begin{array}{c}\text { Not } \\
\text { Significant }\end{array}$ & $-0.025 \sim 0.070$ \\
\hline
\end{tabular}

Note: UC = upward comparison; UCE = upward contrastive emotions; UAE = upward assimilative emotions; $\mathrm{DISC}=$ Instagram discontinuance intention; $\mathrm{MC}=$ the posting of malicious comments; $\mathrm{FC}=$ the posting of favorable comments.

\section{Discussion}

In this study, we comprehensively investigated the relationship between upward social comparison, upward comparison emotions (upward contrastive and assimilative emotions), and three behavioral responses (SNS discontinuance, the posting of malicious comments, and the posting of favorable comments) in the context of Instagram. Furthermore, we explored the mediating effects of upward comparison emotions in the association between upward social comparison and behavioral responses.

\subsection{Main Findings}

Our study found that Instagram users experienced more upward contrastive emotions as they engaged in upward comparison. This result supports previous studies showing that upward comparison on SNSs causes negative upward comparison emotions such as malicious envy [26,27]. Contrary to our expectations, there was no significant association between engaging in upward comparison and upward assimilative emotions. This result may be because the upward social comparison experience does not elicit users' desire to improve themselves; it seems that the assimilative process, a prerequisite for upward assimilative emotions, has not occurred. Additionally, this may be because negative emotions overwhelm positive emotions [26]. Further research is needed on whether and how upward comparison on SNSs elicits positive emotions.

The current study also found that upward comparison emotions are partly related to the three behavioral responses we presented. First, upward contrastive emotions were positively related to Instagram discontinuance intention. This result reflected Wenninger et al. [2], who also found that people want to avoid situations (i.e., Facebook) that cause malicious envy. Thus, our study provides additional evidence in the Instagram context that negative emotions are positively related to discontinuance intention.

Second, upward contrastive emotions were positively related to posting malicious comments that intentionally degrade others. We believe that this is a novel finding. Previous studies have been conducted only in offline or online contexts. Our work extends prior research by showing a positive relationship between negative emotion and malicious commenting in the SNS context. Considering that malicious comments often lead to terrible consequences such as suicide, SNS-induced negative emotions can incur significant socioeconomic costs.

Third, upward contrastive emotions were positively related to posting favorable comments. This finding is contrary to previous studies, which have suggested that anger reduces prosocial behavior in the offline context [34]. A potential explanation for this finding is that, driven by a desire to leave a good impression on other people, SNS users have no choice but to write favorable comments to others' posting even though they feel negative emotions due to social comparison. Lastly, upward assimilative emotions led 
to the posting of favorable comments. This finding extends previous studies conducted in offline and online contexts $[37,38]$ by revealing that positive emotions can also lead to prosocial behavior in the SNS context.

The most obvious finding of this study is that upward comparison causes upward contrastive emotions, leading to the following behavioral consequences: Instagram discontinuance intention and the posting of malicious or favorable comments. This finding implies that negative emotions are an important underlying psychological mechanism in the association between upward social comparison and behavioral responses.

\subsection{Implications}

Our study provides important implications for SNS researchers. Our findings suggest that upward comparison on SNSs should be considered to address questions that SNS researchers have recently become interested in and social issues that have recently emerged worldwide. Since the number of people who leave SNS platforms has been increasing, there has been growing interest among researchers in exploring the antecedents of SNS discontinuance $[45,52,53]$. However, to date, far too little attention has been paid to upward social comparison (with a few exceptions [2]). Therefore, we believe that this study provides a better understanding of the SNS discontinuance phenomenon by showing that upward contrastive emotions are positively related to willingness to quit Instagram. Furthermore, as malicious comments online emerge as a global social issue, some researchers have started to explore factors motivating the posting of malicious comments [3,32,54]; however, these researchers have not yet realized that upward comparison emotions can generate malicious comments. Hence, we believe that the consideration of upward social comparison in these studies can enrich and advance the current understanding of malicious comments that are prevalent online.

Moreover, the present study provides useful practical implications to SNS providers and users in two major ways. First, upward comparison in SNS usage tends to lead people to quit SNSs, which has the potential to threaten the sustainability of SNS platforms [2]. Therefore, to retain users, SNS providers should strive to improve the current SNS features that induce upward comparison. Recently, for example, Instagram decided to remove a feature that shows the number of "Likes"; furthermore, it is considering hiding the number of followers, another feature that can cause social comparison.

Second, it is necessary to realize that one of the major causes of malicious comments may be upward social comparison. Therefore, it is important to reduce the intensity of upward comparison that causes SNS users to post malicious comments. It is recommended that SNSs should be used actively rather than passively, because the active (passive) usage of SNSs is negatively (positively) related to upward comparison [12]. It is also important to regulate negative emotions caused by upward comparison so that negative emotions do not lead to the posting of malicious comments. Hamer and Konijn [55] emphasized the role of emotion regulation strategies, which are intended to change unfavorable feelings due to a negative experience (e.g., upward social comparison), in preventing malicious behavior. They found that negative emotional regulation (e.g., constantly recalling stressful events and thinking about how dreadful they were) can reinforce the adverse impact of negative emotions on cyberbullying behaviors. Thus, SNS users should not engage in negative emotional regulation (e.g., for anger) in response to upward social comparison.

However, SNS platforms should not deny the fact that they are partly responsible for the occurrence of malicious comments. Recently, Instagram has introduced a new anti-cyberbullying feature called "Comment Warning". It automatically detects offensive comments before they are posted, and it warns users that they should rewrite them. However, despite such technical measures, as long as users experience negative emotions due to upward comparison, the number of malicious comments posted online might not be reduced. Therefore, SNS providers need to pay more attention to the underlying causes that drive users to post malicious comments (e.g., upward social comparison). 


\subsection{Limitations and Future Directions}

The present study is not without limitations. First, although we identified potential behavioral responses of upward social comparison, there could be others that we have not covered. For example, users might make impulsive purchases to relieve negative emotions induced by upward social comparison [56]. Second, our sample was comprised only of Instagram users in South Korea. We believe that Instagram is the most relevant SNS for observing the phenomenon of social comparison because it is a very popular image-based platform on which positive self-presentation is very common and comparison-induced features are provided. However, our findings cannot be generalized to different SNS platforms (e.g., Facebook) or cultures (e.g., Western countries); thus, further research is needed in various contexts. Third, our study was conducted using a cross-sectional design, and therefore, causal claims must be interpreted with caution. Further longitudinal or experimental designs are required to ascertain the causality of the relationship proposed in this study. Fourth, our participant sample consisted of adults between the ages of 20-49 years. It is necessary to focus on different age groups (e.g., adolescents) in future studies. Finally, in this study, we focused on upward comparison, which happens frequently in the SNS context. However, some users might compare themselves with those who are worse off (i.e., downward comparison). Thus, it would be interesting to investigate behavioral responses to downward comparison; as shown in our study, negative (or positive) emotions caused by downward comparison need to be taken into account.

\section{Conclusions}

Despite some limitations, our study contributes to the literature on upward social comparison on SNSs by not only identifying three behavioral responses to upward social comparison on Instagram but also revealing that negative upward comparison emotions (i.e., upward contrastive emotions) are an important underlying psychological mechanism in the association between upward social comparison and behavioral responses. We believe that the conceptual model we presented will help SNS researchers to investigate the behavioral consequences of social comparison and the antecedents of SNS discontinuance and the posting of comments online. Considering our findings that upward social comparison can lead to the posting of malicious comments through negative emotions, the social impact of upward comparison may be greater than we know. Thus, policymakers should educate the public about the potential negative consequences of SNS use and pressure SNS platforms to take actions to alleviate the intensity of social comparison. SNS providers and developers need to understand that one of the causes of SNS discontinuance and the posting of malicious comments is social comparison. Overall, our research broadens the current knowledge on how upward comparison on SNSs relates to user behavior and presents future research directions for emerging research topics.

Author Contributions: Conceptualization, J.P. and B.K.; formal analysis, S.P.; methodology, S.P.; writing-original draft, J.P.; writing-review and editing, B.K. and S.P. All authors have read and agreed to the published version of the manuscript.

Funding: This research received no external funding.

Institutional Review Board Statement: Not applicable.

Informed Consent Statement: Informed consent was obtained from all subjects involved in the study.

Data Availability Statement: The data presented in this study are available on request from the corresponding author.

Conflicts of Interest: The authors declare no conflict of interest.

\section{References}

1. Edison Research. 2019. Available online: https://www.edisonresearch.com/infinite-dial-2019/ (accessed on 30 April 2021).

2. Wenninger, H.; Cheung, C.M.; Krasnova, H. College-aged users behavioral strategies to reduce envy on social networking sites: A cross-cultural investigation. Comput. Hum. Behav. 2019, 97, 10-23. [CrossRef] 
3. Kim, H.-M.; Bock, G.-W.; Kim, H.S. A new perspective on online malicious comments: Effects of attention and neutralization. Inf. Technol. People 2020, 34, 50-67. [CrossRef]

4. Jang, Y.J.; Kim, H.W.; Jung, Y. A mixed methods approach to the posting of benevolent comments online. Int. J. Inf. Manag. 2016, 36, 414-424. [CrossRef]

5. Festinger, L. A theory of social comparison processes. Hum. Relat. 1954, 7, 117-140. [CrossRef]

6. Gerber, J.P.; Wheeler, L.; Suls, J. A social comparison theory meta-analysis 60+ years on. Psychol. Bull. 2018, 144, 177. [CrossRef]

7. Lin, R.; Utz, S. The emotional responses of browsing Facebook: Happiness, envy, and the role of tie strength. Comput. Hum. Behav. 2015, 52, 29-38. [CrossRef]

8. Smith, R.H.; Kim, S.H. Comprehending envy. Psychol. Bull. 2007, 133, 46. [CrossRef]

9. Wenninger, H.; Cheung, C.M.; Chmielinski, M. Understanding envy and users' responses to envy in the context of social networking sites: A literature review. Int. J. Inf. Manag. 2021, 58, 102303. [CrossRef]

10. Li, Y. Upward social comparison and depression in social network settings: The roles of envy and self-efficacy. Internet Res. 2019, 29, 46-59. [CrossRef]

11. Liu, Q.Q.; Zhou, Z.K.; Yang, X.J.; Niu, G.F.; Tian, Y.; Fan, C.Y. Upward social comparison on social network sites and depressive symptoms: A moderated mediation model of self-esteem and optimism. Personal. Individ. Differ. 2017, 113, 223-228. [CrossRef]

12. Pang, H. Unraveling the influence of passive and active WeChat interactions on upward social comparison and negative psychological consequences among university students. Telemat. Inform. 2021, 57, 101510. [CrossRef]

13. Wang, W.; Wang, M.; Hu, Q.; Wang, P.; Lei, L.; Jiang, S. Upward social comparison on mobile social media and depression: The mediating role of envy and the moderating role of marital quality. J. Affect. Disord. 2020, 270, 143-149. [CrossRef] [PubMed]

14. Seo, M.; Hyun, K.D. The effects of following celebrities' lives via SNSs on life satisfaction: The palliative function of system justification and the moderating role of materialism. New Media Soc. 2018, 20, 3479-3497. [CrossRef]

15. Olivos, F.; Olivos-Jara, P.; Browne, M. Asymmetric social comparison and life satisfaction in social networks. J. Happiness Stud. 2020, 22, 363-384. [CrossRef]

16. Schmuck, D.; Karsay, K.; Matthes, J.; Stevic, A. “Looking Up and Feeling Down”. The influence of mobile social networking site use on upward social comparison, self-esteem, and well-being of adult smartphone users. Telemat. Inform. 2019, 42, 101240. [CrossRef]

17. Wang, J.L.; Wang, H.Z.; Gaskin, J.; Hawk, S. The mediating roles of upward social comparison and self-esteem and the moderating role of social comparison orientation in the association between social networking site usage and subjective well-being. Front. Psychol. 2017, 8, 771. [CrossRef] [PubMed]

18. Krasnova, H.; Widjaja, T.; Buxmann, P.; Wenninger, H.; Benbasat, I. Research note-Why following friends can hurt you: An exploratory investigation of the effects of envy on social networking sites among college-age users. Inf. Syst. Res. 2015, 26, 585-605. [CrossRef]

19. Latif, K.; Weng, Q.; Pitafi, A.H.; Ali, A.; Siddiqui, A.W.; Malik, M.Y.; Latif, Z. Social comparison as a double-edged sword on social media: The role of envy type and online social identity. Telemat. Inform. 2021, 56, 101470. [CrossRef]

20. Lim, M.; Yang, Y. Effects of users' envy and shame on social comparison that occurs on social network services. Comput. Hum. Behav. 2015, 51, 300-311. [CrossRef]

21. Smith, R.H. Assimilative and contrastive emotional reactions to upward and downward social comparisons. In Handbook of Social Comparison; Springer: Boston, MA, USA, 2000; pp. 173-200.

22. Frijda, N.H. Impulsive action and motivation. Biol. Psychol. 2010, 84, 570-579. [CrossRef]

23. Lazarus, R.S. Progress on a cognitive-motivational-relational theory of emotion. Am. Psychol. 1991, 46, 819. [CrossRef]

24. Lup, K.; Trub, L.; Rosenthal, L. Instagram\# instasad?: Exploring associations among instagram use, depressive symptoms, negative social comparison, and strangers followed. Cyberpsychol. Behav. Soc. Netw. 2015, 18, 247-252.

25. Meier, A.; Schäfer, S. The positive side of social comparison on social network sites: How envy can drive inspiration on Instagram. Cyberpsychol. Behav. Soc. Netw. 2018, 21, 411-417. [CrossRef]

26. Wu, J.; Srite, M. Envy on social media: The good, the bad and the ugly. Int. J. Inf. Manag. 2021, 56, 102255. [CrossRef]

27. Meier, A.; Gilbert, A.; Börner, S.; Possler, D. Instagram inspiration: How upward comparison on social network sites can contribute to well-being. J. Commun. 2020, 70, 721-743. [CrossRef]

28. Mussweiler, T.; Rüter, K.; Epstude, K. The ups and downs of social comparison: Mechanisms of assimilation and contrast. J. Personal. Soc. Psychol. 2004, 87, 832. [CrossRef] [PubMed]

29. Duffy, M.K.; Shaw, J.D. The Salieri syndrome: Consequences of envy in groups. Small Group Res. 2000, 31, 3-23. [CrossRef]

30. Yoshimura, C.G. The experience and communication of envy among siblings, siblings-in-law, and spouses. J. Soc. Pers. Relatsh. 2010, 27, 1075-1088. [CrossRef]

31. Tse, H.H.; Lam, C.K.; Gu, J.; Lin, X.S. Examining the interpersonal process and consequence of leader-member exchange comparison: The role of procedural justice climate. J. Organ. Behav. 2018, 39, 922-940. [CrossRef]

32. Lee, S.H.; Kim, H.W. Why people post benevolent and malicious comments online. Commun. ACM 2015, 58, 74-79. [CrossRef]

33. Jang, Y.J.; Cho, E.Y.; Kim, H.W. An Exploratory Study on Online Prosocial Behavior. Knowl. Manag. Res. 2015, 16, $225-242$.

34. Mesurado, B.; Vidal, E.M.; Mestre, A.L. Negative emotions and behaviour: The role of regulatory emotional self-efficacy. J. Adolesc. 2018, 64, 62-71. [CrossRef] 
35. Richaud, M.C.; Mesurado, B. Positive emotions and empathy as promotors of prosocial behavior and inhibitors of aggressive behavior. Acción Psicológica 2016, 13, 31-42. [CrossRef]

36. Dickerson, K.L.; Skeem, J.L.; Montoya, L.; Quas, J.A. Using Positive Emotion Training With Maltreated Youths to Reduce Anger Bias and Physical Aggression. Clin. Psychol. Sci. 2020, 8, 773-787. [CrossRef]

37. Aknin, L.B.; Van de Vondervoort, J.W.; Hamlin, J.K. Positive feelings reward and promote prosocial behavior. Curr. Opin. Psychol. 2018, 20, 55-59. [CrossRef]

38. Erreygers, S.; Vandebosch, H.; Vranjes, I.; Baillien, E.; De Witte, H. Nice or naughty? The role of emotions and digital media use in explaining adolescents' online prosocial and antisocial behavior. Media Psychol. 2017, 20, 374-400. [CrossRef]

39. Latif, K.; Malik, M.Y.; Pitafi, A.H.; Kanwal, S.; Latif, Z. If you travel, I travel: Testing a model of when and how travel-related content exposure on facebook triggers the intention to visit a tourist destination. Sage Open 2020, 10, 2158244020925511. [CrossRef]

40. Wise App Survey. Available online: https://www.news1.kr/articles/?4164241 (accessed on 30 April 2021).

41. Buunk, A.P.; Gibbons, F.X. Social comparison orientation: A new perspective on those who do and those who don't compare with others. In Social Comparison and Social Psychology: Understanding Cognition, Intergroup, Relations, and Culture; Guimond, D., Ed.; Cambridge University Press: Cambridge, UK, 2006; pp. 15-32.

42. Collins, R.L. For better or worse: The impact of upward social comparison on self-evaluations. Psychol. Bull. 1996, $119,51$. [CrossRef]

43. Solberg, E.C.; Diener, E.; Wirtz, D. Wanting, Having, and Satisfaction: Examining the Role of Desire Discrepancies in Satisfaction with Income. J. Personal. Soc. Psychol. 2002, 83, 725-734. [CrossRef]

44. Park, S.Y.; Baek, Y.M. Two faces of social comparison on Facebook: The interplay between social comparison orientation, emotions, and psychological well-being. Comput. Hum. Behav. 2018, 79, 83-93. [CrossRef]

45. Luqman, A.; Cao, X.; Ali, A.; Masood, A.; Yu, L. Empirical investigation of Facebook discontinues usage intentions based on SOR paradigm. Comput. Hum. Behav. 2017, 70, 544-555. [CrossRef]

46. Bandalos, D.L.; Finney, S.J. Factor analysis: Exploratory and confirmatory. In The Reviewer's Guide to Quantitative Methods in the Social Sciences; Hancock, G.R., Mueller, R.O., Eds.; Routledge: New York, NY, USA, 2010; pp. 93-114.

47. Bagozzi, R.P.; Yi, Y. On the evaluation of structural equation models. JAMS 1998, 16, 74-94. [CrossRef]

48. Muthén, L.K.; Muthén, B.O. Mplus User's Guide, 8th ed.; Muthén \& Muthén: Los Angeles, CA, USA, 2017.

49. Chin, W.W. The partial least squares approach to structural equation modeling. Mod. Methods Bus. Res. 1998, 295, $295-336$.

50. Hayes, A.F. An index and test of linear moderated mediation. Multivar. Behav. Res. 2015, 50, 1-22. [CrossRef]

51. Fornell, C.; Larcker, D.F. Structural equation models with unobservable variables and measurement error: Algebra and statistics. J. Mark. Res. 1981. [CrossRef]

52. Kang, I.; Zhang, Y.; Yoo, S. Elaboration of Social Media Performance Measures: From the Perspective of Social Media Discontinuance Behavior. Sustainability 2020, 12, 7962. [CrossRef]

53. Maier, C.; Laumer, S.; Eckhardt, A.; Weitzel, T. Giving too much social support: Social overload on social networking sites. Eur. J. Inf. Syst. 2015, 24, 1-18. [CrossRef]

54. Hwang, J.; Lee, H.; Kim, K.; Zo, H.; Ciganek, A.P. Cyber neutralisation and flaming. Behav. Inf. Technol. 2016, 35, 210-224. [CrossRef]

55. Den Hamer, A.H.; Konijn, E.A. Can emotion regulation serve as a tool in combating cyberbullying? Personal. Individ. Differ. 2016, 102, 1-6. [CrossRef]

56. Liu, P.; He, J.; Li, A. Upward social comparison on social network sites and impulse buying: A moderated mediation model of negative affect and rumination. Comput. Hum. Behav. 2019, 96, 133-140. [CrossRef] 